\title{
Precipitation Type Specific Radar Reflectivity-rain Rate Relationships for Warsaw, Poland
}

\author{
Paweł LICZNAR ${ }^{1}$ and Witold F. KRAJEWSKI ${ }^{2}$ \\ ${ }^{1}$ Faculty of Environmental Engineering, Wroclaw University of Technology, \\ Wrocław, Poland; e-mail: pawel.licznar@pwr.edu.pl (corresponding author) \\ IIHR - Hydroscience \& Engineering, University of Iowa, Iowa City, USA; \\ e-mail: witold-krajewski@uiowa.edu
}

\begin{abstract}
Implementation of weather radar precipitation estimates into hydrology, especially urban hydrology practice in Poland, requires the introduction of more precise radar reflectivity versus rain rate (Z-R) relationships accounting for drop size distribution (DSD) specific for different precipitation phases. We explored the development of precipitation type dependent Z-R relationship on the basis of approximately two years of DSD recordings at high temporal resolution of ten seconds. We divided the recorded data into four separate precipitation-type groups: rain, snow, rain-with-snow, and hail. The Z-R relationships for rain and rainwith-snow showed a strong resemblance to the well-known MarshallPalmer Z-R power-type relationship for rain. In the case of snowfall, we found that both the multiplication factor and the exponent coefficients in the Z-R formula have smaller values than for rain. In contrast, for hail precipitation these parameters are higher than for rain, especially the multiplication factor.
\end{abstract}

Key words: Z-R relations, laser disdrometer, hydrometeor types, dual polarization radar.

Ownership: Institute of Geophysics, Polish Academy of Sciences;

(C) 2016 Licznar and Krajewski. This is an open access article distributed under the Creative Commons Attribution-NonCommercial-NoDerivs license,

http://creativecommons.org/licenses/by-nc-nd/3.0/. 


\section{INTRODUCTION}

The advantage of radar technique application for precipitation monitoring comes from its fast measurements over large areas with high temporal and spatial resolution, thus satisfying most of the current operational hydrology needs. However, rainfall sampling with analogous spatial resolution with the application of rain gauge networks remains practically impossible, as could be illustrated by the Polish weather radar network, POLRAD. For example, based on estimates presented by Bringi and Chandrasekar (2001), deploying a single gauge for each spatial sample of any POLRAD C-band radar $(1 \mathrm{~km}$ resolution in range and one-degree resolution in azimuth) would require 90000 gauges over a circular domain with $250 \mathrm{~km}$ radius. While these numbers represent an exaggeration, they make it clear that the complications involved with installing a large number of instruments at high spatial density, especially in urban environments, combined with the difficulty of developing effective transmission networks and centralized systems allowing for the online gauge systems' receiving and processing of data, renders the project infeasible. In contrast, radar measurements are sent to a central location at the speed of light by "natural networks" (Bringi and Chandrasekar 2001). The available radar products from the POLRAD system most often employed by the hydrological community - the Constant Altitude Plan Position Indicator (CAPPI) or Surface Rainfall Intensity (SRI) - cover most of Poland. Their real spatial resolution depends on technical parameters of the radar systems such as beam width and pulse length, scanning strategy, and distance to radar. Regardless, in case of majority of Poland's biggest cities located in close vicinity up to about $100 \mathrm{~km}$ from POLRAD radars, CAPPI and SRI resolution is equal to $1 \mathrm{~km}^{2}$. This is also the case for Warsaw, wherein for comparison the densest nationwide network of 25 gauges covers some $520 \mathrm{~km}^{2}$ area of the city and provides much sparser information on precipitation spatial distribution, limiting the coverage to one instrument per $21 \mathrm{~km}^{2}$ (Licznar et al. 2015).

While not the focus on this paper, we cannot ignore the associated concerns about the accuracy of radar measurements, as recently reviewed by Villarini and Krajewski (2010), among others. Some approaches for the quantitative uncertainty characterization of radar-based precipitation include a quality index scheme designed to evaluate the quality of different radarderived rainfall products, including processed radar data and precipitation accumulations developed by Szturc et al. (2011) for the POLRAD system. This paper focuses only on possible improvements of final radar-derived precipitation estimates due to the introduction of precipitation-type specific radar reflectivity-precipitation relationships for the local conditions of Warsaw, Poland. These relationships, known as Z-R relationships, are in fact 
empirical formulas of fundamental importance from the perspective of weather radar implementation in hydrology. They are also known to be strongly time dependent as a result of Drop Size Distribution (DSD) fluctuations in time, driven by precipitation phase changes (rain, snow, rain-withsnow, hail, or graupel) and additionally modified by changing intensities and types of precipitation (convective or non-convective). Lee and Zawadzki (2005) argued that "the variety of physical processes leading to variability of DSDs is a key limitation in radar rainfall estimation".

Until recently, accounting for time-dependence DSDs of hydrometeors and thus adjusting precipitation-phase-dependent Z-R relationships was impossible in operational use of weather radars. Derived originally by Marshall et al. (1947) and Marshall and Palmer (1948), the common approach used to determine Z-R relationships, especially for summer periods dominated by rain-type precipitation, does not correlate well with the radar-derived precipitation measurements of temporal readings of nearby gauges. However, for longer time periods much better agreement between radar- and gaugerecorded precipitation totals is observed. Moreover, as also observed in the case of the Warsaw precipitation field by Jakubiak et al. (2014), the radarestimated and gauge-recorded 15-minute rainfall intensities proved to have similar statistical distributions for reasonably long time periods. However, the existence of only statistical agreement between gauge-readings and radar-estimates at sub-hourly time scales reduced the potential usability of radar in hydrology, especially in urban hydrology.

This issue could, however, be at least partially solved today by the introduction of modern disdrometers allowing for on-line recording of DSDs and thus on-line adjustment of Z-R relationships, and by widespread use of new generation dual-polarization radars. The advent of dual-polarization radars resulted in significantly higher accuracies in the estimates of hydrometeor types and, in some cases, even hydrometeor amounts. Bringi and Chandrasekar (2001) uncovered useful information about hydrometeors in the covariance matrix measurements of dual-polarization radars. They achieved hydrometeor classification by radar data processing which implemented some relatively simple empirical algorithms and some more advanced fuzzy logic methods. However, we admit that operational surface precipitation type (SPT) classification systems solely based on dual-polarization radars signals are rather a goal than an already accomplished task by the radar community. Recent developments at SPT systems are driven by the need for reliable data concerning the possible presence of snow or ice for road authorities and not so much by the idea of more precise hydrometeortype dependent Z-R relationships. In addition, the mentioned SPT systems are coupling signals not only from radars but also from additional sources such as ground sensors, weather prediction models, or combinations of both 
(see, e.g., Bech et al. 2014, Gill et al. 2012, Gjertsen and Ødegaard 2005). Finally, the accuracy of the SPT systems is still far from adequate. As it was observed by Gjertsen and Ødegaard (2005), the relative frequency of correct prediction of rain based on HRLAM (High Resolution Limited Area Model) numerical prediction model with adjustment to actual topography reached $86 \%$, whereas low hit rates were found for sleet predictions for all SPT models. Nonetheless, in view of increasing widespread use of radar precipitation estimates, the efforts in estimation of precipitation-phase-dependent Z-R relationships should be undertaken in parallel to the SPT systems improvement.

Currently, the POLRAD system uses modern dual-polarization radars. At selected locations, new Meteor 1600C radars replaced the old generation single-polarization Gematronik Meteor 360AC radars. Given the current and future needs of urban hydrology users, and given the increased interest in the installation of local X-band radars, the use of dual-polarization radars would further increase the interest in radar rainfall precise estimation based on more reliable precipitation-type adjusted Z-R relationships. This study, then, will focus on the development of precipitation-type specific radar reflectivity-rain rate relationships for the local conditions of Warsaw, Poland. We used laser disdrometer records from relatively short period of about two years and provide insight into the contribution of different precipitation phases into total precipitation duration time and amount.

\section{MATERIAL AND METHODS}

For this study, we employed reflectivity and precipitation time series collected by an OTT Parsivel 2 laser disdrometer. We recorded these time series with a temporal resolution of $10 \mathrm{~s}$ using the instrument installed on roof of the Warsaw University, Institute of Geophysics' building in Warsaw, Poland (Fig. 1). We used recordings of precipitations for an approximately two-year period, beginning 13 December 2012 through 30 November 2014. Earlier, Licznar and Siekanowicz-Grochowina (2015) used a single-year portion (2013) of this series, to develop a general Z-R relationship for Warsaw.

The OTT Parsivel 2 disdrometer belongs to the group of the most popular single laser beam optical instruments that allow for on-line recording of DSD. The receiver mounted on the opposite arm of the Y-shaped mast records changes in the voltage created when hydrometeors cross the laser beam (Fig. 1, right panel). In the absence of precipitation and any falling hydrometeors, the maximum voltage is output at the receiver. Hydrometeors passing through the laser beam block off a portion of the beam proportional to their diameter. This results in a proportional decrease in the receiver output voltage that is then used in calculating the hydrometeors' sizes. Single hydrome- 


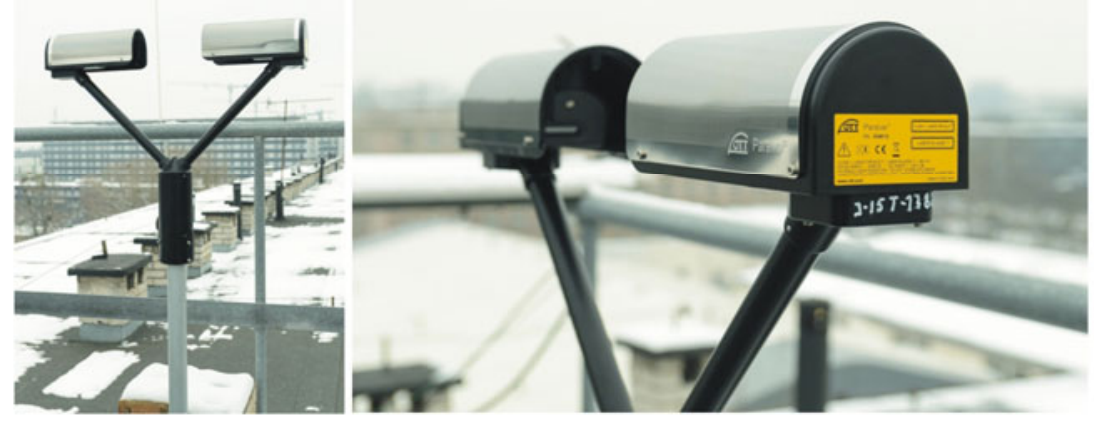

Fig. 1. OTT Parsivel 2 laser disdrometer installed on the observational deck of the roof of the Warsaw University, Institute of Geophysics' building.

teors'falling speeds are calculated from the recorded durations of the output voltage drops. All the hydrometeors for the chosen probing intervals are divided into separate categories based on their diameters and falling velocities. Hydrometeors are classified into 32 classes according to their diameter and speed (ranging, respectively, from 0 to $26 \mathrm{~mm}$ and from 0 to $22.4 \mathrm{~m} \cdot \mathrm{s}^{-1}$ ), leading to a final DSD in the form of a two-dimensional distribution stored as a matrix of $32 \times 32$ dimension (Present Weather Sensor OTT Parsivel 2 manual; OTT 2015).

We further processed DSD using the Parsivel 2 built-in processor, leading to calculation parameters characterizing precipitation. Among these are precipitation rate and radar-reflectivity, which are statistical moments of DSD, of the order of 3 and 6, respectively. For a unit volume of one cubic meter, these moments are defined as follows:

$$
\begin{aligned}
& R=\frac{\pi}{6} \int_{0}^{\infty} N(D) D^{3} V_{t}(D) d D, \\
& Z=\sum_{i=1}^{N} D_{i}^{6}=\int_{0}^{\infty} N(D) D^{6} d D,
\end{aligned}
$$

where $R$ is rain rate $\left[\mathrm{mm} \cdot \mathrm{h}^{-1}\right], Z$ is radar-reflectivity $\left[\mathrm{mm}^{6} \cdot \mathrm{m}^{-3}\right], D_{i}$ is diameter of the $i$-th particle [mm], $N_{i}$ is the number of particles, and $V_{t}$ is the drop terminal velocity $\left[\mathrm{cm} \cdot \mathrm{s}^{-1}\right]$. Keeping in mind the fact that Parsivel 2 is a single-beam laser instrument and due to already discussed technique of hydrometeors' sizing, diameter estimates used in Eqs. 1 and 2 should be identified with horizontal diameter of hydrometeors. Nonetheless, the possible errors induced by the use of horizontal diameter values instead of volumetric dia- 
meter values are concealed by the numerical implementation of Eqs. 1 and 2 by the device built-in processor. Note that integral calculations are performed for DSD ranges but not for single hydrometeors.

In fact, radar-reflectivity, as derived from Eq. 2, is not saved in Parsivel reports in original units but in logarithmic scale of decibels. In general, in weather radar technology, recording of reflectivity at original units of $\mathrm{mm}^{6} \cdot \mathrm{m}^{-3}$ is not used due to the wide dynamic range of its values and their tendency to be error prone. Instead, a logarithmic $d B Z$ scale is found to be more useful:

$$
Z_{d B Z}=10 \log _{10} Z_{m m^{6} m^{-3}},
$$

The Parsivel 2 built-in processor also uses recorded DSDs for the identification of measurement intervals of precipitation and for their classification to one of the eight precipitation types, as shown in Table 1. This classification precedes the calculation of precipitation rate values, as some precipitation-type dependent corrections are introduced in calculated equivalent rain rates. These corrections are only declared and not disclosed in detail by the manufacturer (OTT 2015). The necessity of such correction terms is obvious. As Licznar (2009) observed, in the previous version of the instrument (Parsivel 1), precipitations recorded by disdrometer were typically characterized by higher rates in comparison to electronic weighing gauge readings, especially in the case of rain-with-snow precipitation.

For the purpose of this study, we classified the original eight categories of precipitation types recorded by the OTT Parsivel 2 disdrometer (as seen in Table 1) into four general precipitation-type groups named as: rain, rainwith-snow (or sleet), snow, and hail. This observational set generalization allowed us to analyze some precipitation types such as snow grains that are too rare to be analyzed independently in current (rather short length) precipitation time series. We also distinguished between some very similar forms of hydrometeors that would not be identified by the dual polarization radars' operational use. We believe, however, that a more detailed analysis of all eight precipitation phases would be feasible for a longer disdrometer series.

We divided the total set of accessible $Z$ and $R$ pairs recorded by the Parsivel into four separate subsets, each covering a separate precipitation type. For every subset, we fitted Z-R relationships according to the most widely implemented power-type function:

$$
Z=a R^{b} .
$$

We performed an estimation of $a$ and $b$ parameters in Eq. 4 at logarithmic scales of $Z$ and $R$. We simplified the fitted power-type functions to linear form: 
Table 1

Clustering of precipitation types as classified by OTT Parsivel 2 disdrometer into four distinctive precipitation groups

\begin{tabular}{|c|c|c|c|c|c|}
\hline $\begin{array}{l}\text { Precipitation } \\
\text { type group }\end{array}$ & $\begin{array}{c}\text { Precipitation } \\
\text { type }\end{array}$ & Intensity & $\begin{array}{l}\text { Rain rate, } \\
{\left[\mathrm{mm} \cdot \mathrm{h}^{-1}\right]}\end{array}$ & NWS & $\begin{array}{l}\text { METAR/SPECI } \\
\mathrm{w}_{\mathrm{a}} \mathrm{w}_{\mathrm{a}} \text { Table } 4678\end{array}$ \\
\hline \multirow{3}{*}{ Rain } & Drizzle & $\begin{array}{l}\text { light } \\
\text { moderate } \\
\text { heavy } \\
\end{array}$ & $\begin{array}{l}\leq 0.2 \\
0.2 \ldots 0.5 \\
\geq 0.5\end{array}$ & $\begin{array}{l}\mathrm{L}- \\
\mathrm{L} \\
\mathrm{L}+\end{array}$ & $\begin{array}{r}-\mathrm{DZ} \\
\mathrm{DZ} \\
+\mathrm{DZ} \\
\end{array}$ \\
\hline & $\begin{array}{l}\text { Drizzle } \\
\text { with rain }\end{array}$ & $\begin{array}{l}\text { light } \\
\text { moderate } \\
\text { heavy }\end{array}$ & $\begin{array}{l}\leq 0.2 \\
0.2 \ldots 0.5 \\
\geq 0.5\end{array}$ & $\begin{array}{l}\text { RL- } \\
\text { RL } \\
\text { RL+ }\end{array}$ & $\begin{array}{r}- \text { RADZ } \\
\text { RADZ } \\
+ \text { RADZ }\end{array}$ \\
\hline & Rain & $\begin{array}{l}\text { light } \\
\text { moderate } \\
\text { heavy }\end{array}$ & $\begin{array}{l}\leq 0.5 \\
0.5 \ldots 7.5 \\
\geq 7.5\end{array}$ & $\begin{array}{l}\mathrm{R}- \\
\mathrm{R} \\
\mathrm{R}+\end{array}$ & $\begin{array}{r}-\mathrm{RA} \\
\mathrm{RA} \\
+\mathrm{RA}\end{array}$ \\
\hline \multirow{2}{*}{$\begin{array}{l}\text { Rain } \\
\text { with snow }\end{array}$} & $\begin{array}{l}\text { Rain, } \\
\text { drizzle } \\
\text { with snow }\end{array}$ & $\begin{array}{l}\text { light } \\
\text { moderate } \\
\text { heavy }\end{array}$ & $\begin{array}{l}\leq 0.5 \\
>0.5\end{array}$ & $\begin{array}{l}\text { RLS- } \\
\text { RLS } \\
\text { RLS+ }\end{array}$ & $\begin{array}{r}- \text { RASN } \\
\text { RASN } \\
+ \text { RASN }\end{array}$ \\
\hline & $\begin{array}{l}\text { Freezing } \\
\text { rain }\end{array}$ & $\begin{array}{l}\text { light } \\
\text { moderate } \\
\text { heavy }\end{array}$ & $\begin{array}{l}\leq 0.4 \\
>0.4\end{array}$ & $\begin{array}{l}\text { SP } \\
\text { SP } \\
\text { SP }\end{array}$ & $\begin{array}{r}-\mathrm{GS} \\
\mathrm{GS} \\
+\mathrm{GS}\end{array}$ \\
\hline Snow & Snow & $\begin{array}{l}\text { light } \\
\text { moderate } \\
\text { heavy }\end{array}$ & $\begin{array}{c}\leq 0.5 \\
0.5 \ldots 2.5 \\
>2.5\end{array}$ & $\begin{array}{l}\mathrm{S}- \\
\mathrm{S} \\
\mathrm{S}+\end{array}$ & $\begin{array}{r}-\mathrm{SN} \\
\mathrm{SN} \\
+\mathrm{N}\end{array}$ \\
\hline \multirow[t]{2}{*}{ Hail } & $\begin{array}{l}\text { Snow } \\
\text { grains }\end{array}$ & $\begin{array}{l}\text { light } \\
\text { moderate } \\
\text { heavy }\end{array}$ & $\begin{array}{c}\leq 0.5 \\
0.5 \ldots 4.0 \\
>4.0\end{array}$ & $\begin{array}{l}\mathrm{SG} \\
\mathrm{SG} \\
\mathrm{SG}\end{array}$ & $\begin{array}{r}-\mathrm{SG} \\
\mathrm{SG} \\
+\mathrm{SG}\end{array}$ \\
\hline & Hail & $\begin{array}{l}\text { light } \\
\text { moderate }\end{array}$ & $\begin{array}{l}\leq 7.5 \\
>7.5\end{array}$ & $\begin{array}{l}\mathrm{A} \\
\mathrm{A}\end{array}$ & $\begin{array}{r}-\mathrm{GR} \\
\mathrm{GR}\end{array}$ \\
\hline
\end{tabular}

Notice: Precipitation-type characteristics and descriptions by means of NWS and METAR/SPECI are based on Present Weather Sensor OTT Parsivel 2 manual.

$$
\log _{10} Z=b\left(\log _{10} R\right)+\log _{10} a .
$$

We worked with logarithmic scales since the analyzed sets did not have uniform distributions and were dominated by small or moderate values. Additional aspects of our choice are discussed in Ciach and Krajewski (1999). 
In view of Eq. 5 we also used logarithmic $d B R$ scale in case of rainfall rate, defined similarly to Eq. 3:

$$
R_{d B R}=10 \log _{10} R_{m m h^{-1}}
$$

Finally, we derived the results of precipitation-phase dependent $a$ and $b$ parameters together with their $95 \%$ confidence intervals. We compared the obtained parameter values with analyzed precipitation types and discussed our findings with reference to the available literature.

Given the material and methods presented above, we would like to note four important limitations of the conceptual and practical aspects of our study. First, we did not have access to other sources of additional information, e.g., weighing rain gauge time series, radar scans or local synoptic station records. Because of this, we were not able to verify the quality of our data, i.e., to verify the measured reflectivity and precipitation rate values, and examine the relevance of SPT classification of hydrometeors by the disdrometer. Second, since series of $Z$ and $R$ are calculated from the same DSDs, we might except a prior strong correlation of regressive formulas. Third, we worked only with the calculated radar reflectivity values based on DSD, that are not fully equivalent to the simultaneous measurements of radar. Instead of the radar reflectivity, reflectivity factor is the really measured quantity by radar, which depends upon many other factors as radar frequency, polarization, etc. Fourth, lacking synoptic information, we mixed in our precipitation-type dependent Z-R datasets, observations belonging to various types of precipitation systems. Note that, as discussed in detail by Ochou et al. (2011), convective and stratiform precipitation systems could be characterized by diverse Z-R relationships. Thus, we do not recommend direct and indiscriminate implementation of our results into POLRAD system precipitation processing. Despite these shortcomings, we believe our work should be considered as a first step into improvement of radar based precipitation products accessible for urban hydrology in Warsaw and further, more advanced DSD studies, as conducted by Ochou et al. (2011) for old-type Joss Waldvogel RD-69 disdrometer series.

\section{RESULTS AND DISCUSSION}

We found that the total duration time of precipitations of all types was equal to $7.1 \%$ of the total duration time of the analyzed precipitation time series. This means that for $92 \%$ of the time series, precipitation intermittency was observed. This remains in agreement with earlier observations reported by Licznar et al. (2015) in which the probability of zero rainfall intervals at the observational series originating from Warsaw gauges was about $94 \%$. Small differences in those values could be explained by differences in analyzed 

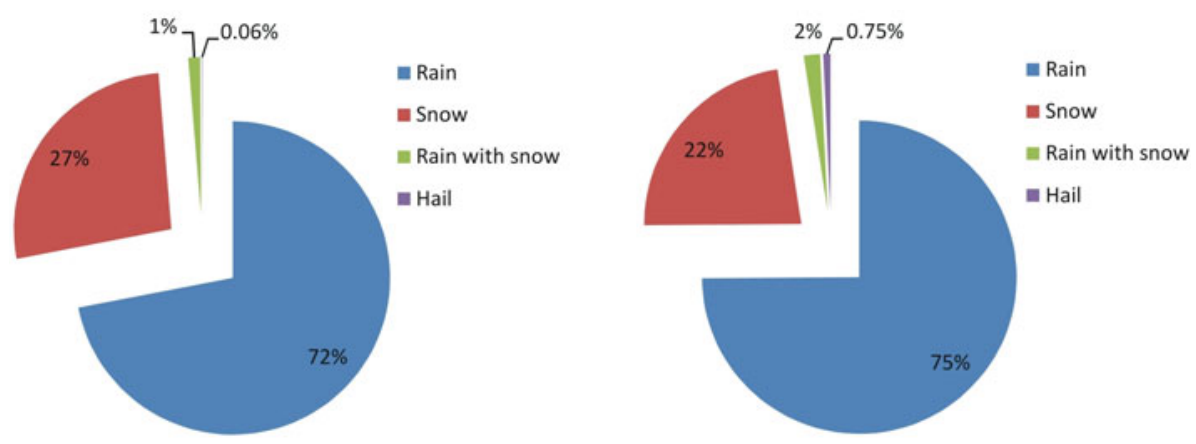

Fig. 2. Share of different precipitation-type groups in total recorded precipitation duration time (left panel) and in total precipitation (right panel).

years and the resolution of series analysis. Figure 2 shows the share of different precipitation types in total recorded precipitation time and in total precipitation; rain dominates, delivering $75 \%$ of its total in Warsaw. Rain-withsnow and hail types are much less frequent and contribute only marginally to the precipitation totals.

Table 2 summarizes the basic statistical parameters of analyzed Z-R subsets for different precipitation-type groups. On the basis of these data, we observed distinctive high values of reflectivity ranges for hail, associated with extremely high precipitation rates, exceeding even $140 \mathrm{~mm} \cdot \mathrm{h}^{-1}$. We also observed high precipitation rates in the case of rain, but the maximum is still about $20 \mathrm{~mm} \cdot \mathrm{h}^{-1}$ less than for hail. Snow and rain-with-snow precipitation rates and reflectivities on average are not far from the rainfall average rate but their maximum values are at least twofold smaller. Regardless of that, maximum radar reflectivities in all subsets, except hail, do not exceed $56.8 \mathrm{dBZ}$. Note that for radar rain rate estimation in the operational use of Marshall-Palmer Z-R relationships or the similar type of equation specific for WSR-88D radars, the maximum $Z$ is usually truncated at $55 \mathrm{dBZ}$, to avoid hail contamination (Bringi and Chandrasekar 2001).

Table 2

Statistics characterizing observational subsets for different precipitation-type groups

\begin{tabular}{|l|r|c|r|c|r|c|c|}
\hline $\begin{array}{c}\text { Precipitation- } \\
\text { type group }\end{array}$ & $n$ & $\begin{array}{c}R_{\min } \\
{\left[\mathrm{mm} \cdot \mathrm{h}^{-1}\right]}\end{array}$ & $\begin{array}{c}R_{\max } \\
{\left[\mathrm{mm} \cdot \mathrm{h}^{-1}\right]}\end{array}$ & $\begin{array}{c}\text { Average } R \\
{\left[\mathrm{~mm} \cdot \mathrm{h}^{-1}\right]}\end{array}$ & $\begin{array}{c}Z_{\min } \\
{[\mathrm{dBZ}]}\end{array}$ & $\begin{array}{c}Z_{\max } \\
{[\mathrm{dBZ}]}\end{array}$ & $\begin{array}{c}\text { Average } Z \\
{[\mathrm{dBZ}]}\end{array}$ \\
\hline Rain & 277773 & 0.007 & 124.341 & 1.006 & -10.0 & 56.5 & 27.7 \\
Snow & 103189 & 0.078 & 62.763 & 0.820 & 0.9 & 56.8 & 23.0 \\
Rain-with-snow & 4726 & 0.115 & 48.848 & 1.337 & 8.0 & 53.8 & 28.9 \\
Hail & 233 & 0.490 & 141.022 & 26.242 & 20.0 & 60.8 & 51.4 \\
\hline
\end{tabular}


Analyzing the data in Table 2 we should remember that indicated statistics are retrieved from statistical populations of 10-second recordings. If so, the expected range of min-max values could clearly extend beyond ranges of precipitation rates and reflectivity factors recorded by radars and averaged usually for longer scanning times of about $10 \mathrm{~min}$. This could, at least to some extent, explain rare but still unexpectedly high values of $R$ and $Z$ recordings for snow (maximum equal to $62.8 \mathrm{~mm} \cdot \mathrm{h}^{-1}$ and $56.8 \mathrm{dBZ}$, respectively) or very small reflectivity readings for rain with minimum of $-10 \mathrm{dBZ}$. We also believe that the reported singularities may result, firstly, from disdrometer errors related to the precision of real hydrometers sizing for very small as well as very big irregular particles and, secondly, from precipitation type misclassification by the instrument. For sure, single beam laser disdrometer is not a perfect SPT classification system.

Table 3

Parameters of reflectivity-rain rate Z-R relationships

and values describing the models' fits for different precipitation type groups

\begin{tabular}{|l|c|c|c|c|}
\hline $\begin{array}{c}\text { Precipitation- } \\
\text { type group }\end{array}$ & $R^{2}$ & $\begin{array}{c}\mathrm{RMSE} \\
\log _{10}\left[\mathrm{~mm}^{6} \cdot \mathrm{m}^{-3}\right]\end{array}$ & $a$ & $b$ \\
\hline Rain & 0.9288 & 0.2354 & $\begin{array}{c}\mathbf{1 9 1 . 4 0 6} \\
(190.944,191.869)\end{array}$ & $\begin{array}{c}\mathbf{1 . 5 6 3} \\
(1.562,1.565)\end{array}$ \\
\hline Snow & 0.8489 & 0.2140 & $\begin{array}{c}\mathbf{1 0 6 . 6 4 4} \\
(106.253,107.036)\end{array}$ & $\begin{array}{c}\mathbf{1 . 4 3 6} \\
(1.433,1.440)\end{array}$ \\
\hline Rain with snow & 0.8382 & 0.2312 & $\begin{array}{c}\mathbf{2 1 2 . 0 5 0} \\
(208.714,215.438)\end{array}$ & $\begin{array}{c}\mathbf{1 . 5 3 4} \\
(1.515,1.554)\end{array}$ \\
\hline Hail & 0.8823 & 0.3608 & $\begin{array}{c}\mathbf{5 7 3 . 2 4 4} \\
(460.280,713.932)\end{array}$ & $\begin{array}{c}\mathbf{1 . 6 1 4} \\
(1.538,1.690)\end{array}$ \\
\hline
\end{tabular}

Figures 3-6 show precipitation-type dependent Z-R relationships; their fit parameters according to Eqs. 4 and 5 are summarized in Table 3 . In all four cases, developed relationships were characterized by high correlation values, with $R^{2}$ at the range from 0.88 to 0.92 , and small root mean square error values. We found that the rain-type subset - the most numerous - had the highest correlation values, with the number of Z-R pairs equal to 277773 (Table 2). Nevertheless, for a 3 orders less numerous hail precipitation subset, the correlation coefficient remained at a fairly high level and the $95 \%$ confidence intervals shown in Fig. 6 were narrow. Even narrower 95\% intervals were found for other subsets and, in the case of rain-and-snow relationships, they were masked at the scales shown in Figs. 3 and 4.

As expected, reflectivity-rain rate Z-R relationship values for rain were very close to the well-known values of $a=200$ and $b=8 / 5$, as originally 


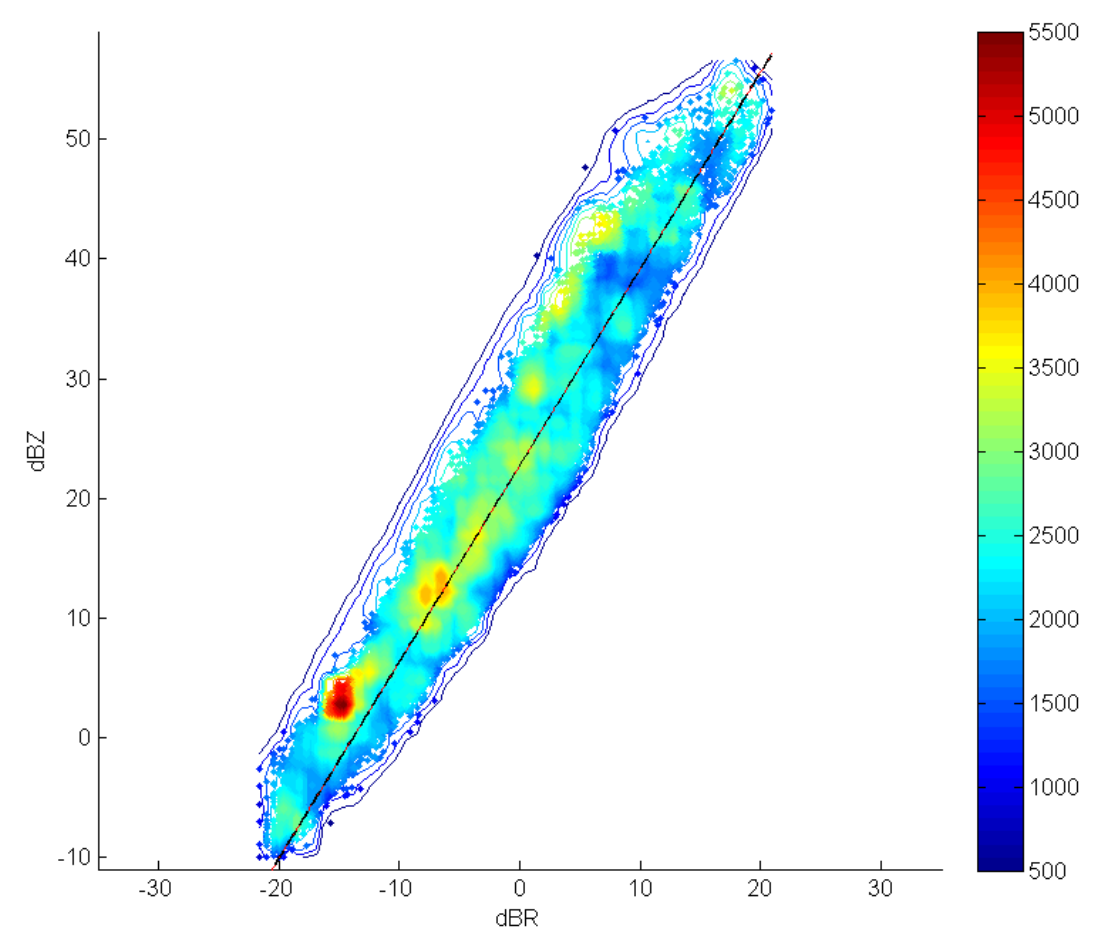

Fig. 3. Z-R functional relationships for Warsaw, developed for rain precipitation based on laser disdrometer records. Local density of often overlapped experimental point is shown as color map with isolines. This fitted linear model is plotted as a solid line and its $95 \%$ confidence intervals are not visible at the scale of the figure.

published by Marshall et al. (1947) and Marshall and Palmer (1948). Because the rain-type precipitation dominated the whole data set with respect to both the total duration time and precipitation total, it was also not surprising that the Z-R relationship parameters in Table 3 were not far from the parameters $(a=155.1$ and $b=1.528)$ found by Licznar and SiekanowiczGrochowina (2015) for the 2013 year-long precipitation series from Warsaw. Similarly, the Z-R relationship for rain-with-snow for Warsaw was very close to the rain-specific equation. This could be explained by the close proximity of both precipitation-type groups with respect to recorded DSDs. As stressed by Gjertsen and Ødegaard (2005), there is no definition for sleet in terms of mixing ratio and the low hit ratio for this class is observed in SPT systems in general.

Moving from the rain data and rain-with-snow subsets to the purely snow subset, we observed a sharp decrease of both $a$ and $b$ parameters, up to 106.6 and 1.436 , respectively. We predicted this sharp change in $a$ and $b$ pa- 


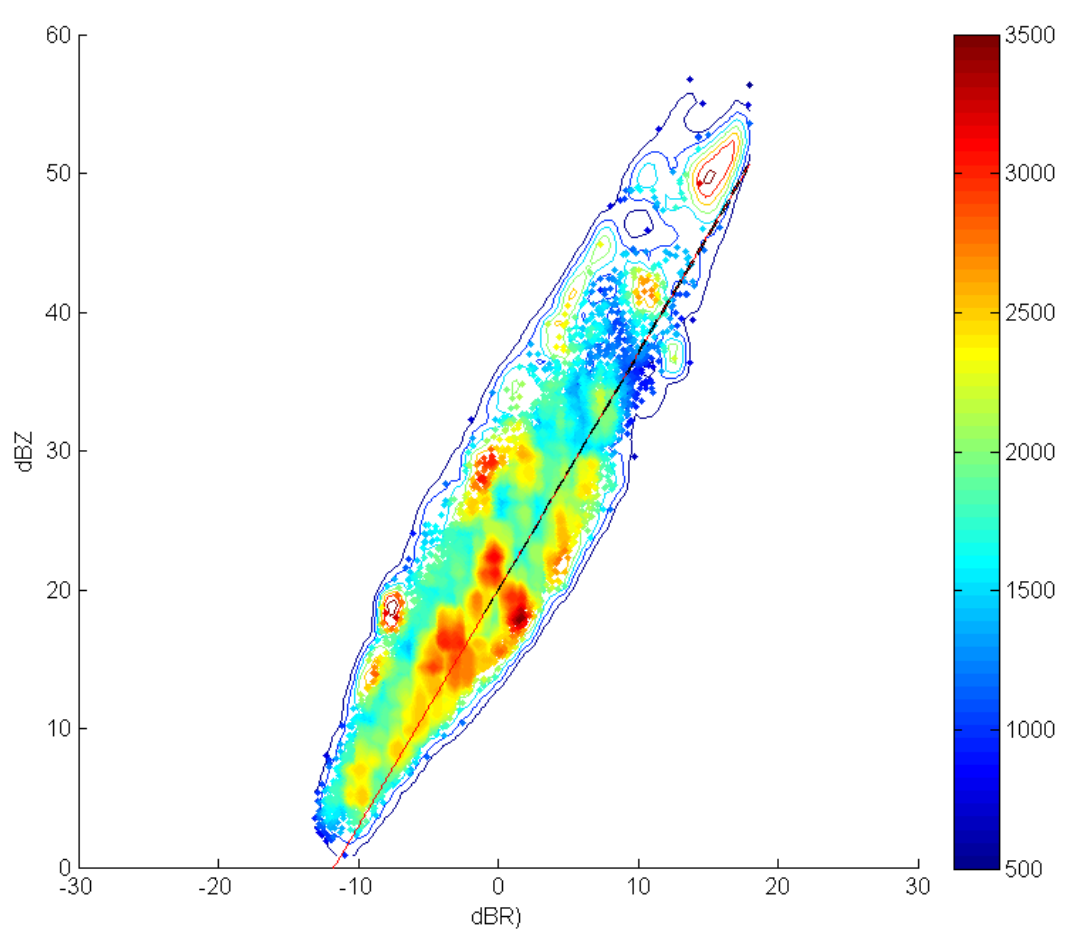

Fig. 4. Z-R functional relationships for Warsaw, developed for snow precipitation based on laser disdrometer records. Local density of often overlapped experimental point is shown as color map with isolines. This fitted linear model is plotted as solid line and its $95 \%$ confidence intervals are not visible at the scale of the figure.

rameters given that Eq. 2 reflectivity is most sensitive to drop diameter. Any change in drop diameter or more precisely substitution of raindrops by bigger sized snowflakes would increase the reflectivity. Nevertheless, the values provided in Table 3 are difficult to compare directly with other results, even from climates fairly close to central Poland, since no Z-R relationships have been published for the central European region. In the USA, according to FCM-H11B-2005, a mean Z-R relationship for snow is suggested to have $a=200$ and $b=2$ values, whereas $R$ is considered to be an equivalent rain rate. In the same publication, however, it also acknowledged that the best Z-R relationship depends significantly on geographic location, and WSR88D (Weather Surveillance Radar - 1988 Doppler; OFCM 2005) Radar Operations Center (ROC) recommends that the Z-R relationships have values of $a=130$ and $b=2.0$ for winter stratiform precipitation (east of the Continental Divide) and orographic rain (East), and $a=75$ and $b=2.0$ for winter stratiform precipitation (west of the Continental Divide) and orographic 


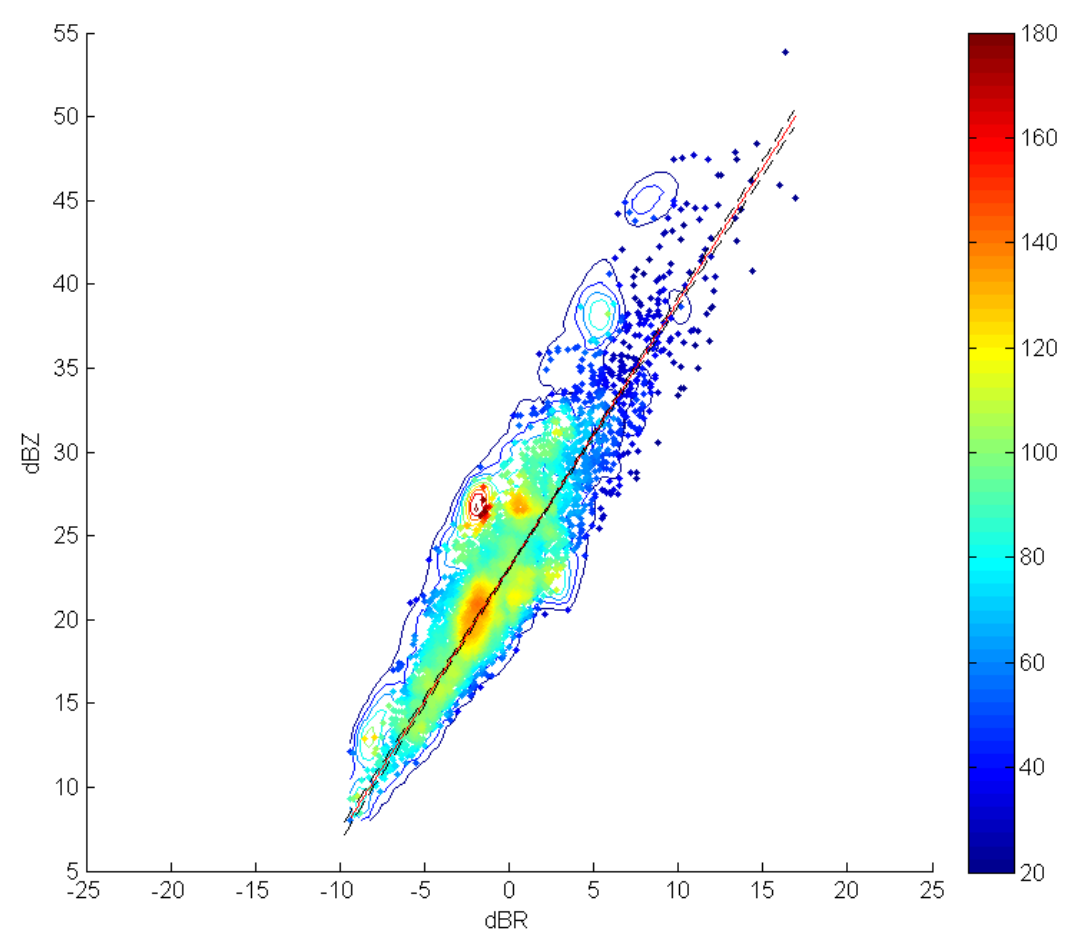

Fig. 5. Z-R functional relationships for Warsaw, developed for rain-with-snow precipitation based on laser disdrometer records. Local density of often overlapped experimental point is shown as color map with isolines. This fitted linear model is plotplotted as solid line and its $95 \%$ confidence intervals are drawn by dotted lines.

rain (West). Vasiloff (2002) recommends that the application of the last pair of parameters be used everywhere with additional corrections for mountains and valleys within an approximately $100 \mathrm{~km}$ of the radar. However, owing to the significant differences between continental US climates and European temperate climates, results from Warsaw would more likely align with the values in Cyr's study (Cyr 2014). Based on Parsivel disdrometer data, Cyr estimated $a$ and $b$ parameters to be equal to 152.1 and 1.552 , respectively, for stratiform class snow precipitations. In the case of a Warsaw-specific Z$\mathrm{R}$ relationship for snow, the $a$ parameter would be similar to the range of US-based relations, whereas its $b$ parameter is much smaller and thus closer to the value found in Norway. From a theoretical microphysics perspective, the value of $b$ equal to 1.552 as reported by Cyr (2014) for snow should rather be associated with rain. Dotzek and Beheng (2001) found the $b$ parameter to be around $1.55 \pm 0.05$ in the case of rain-dominated precipitation, when the drops' fall speeds are proportional to the root square of their di- 


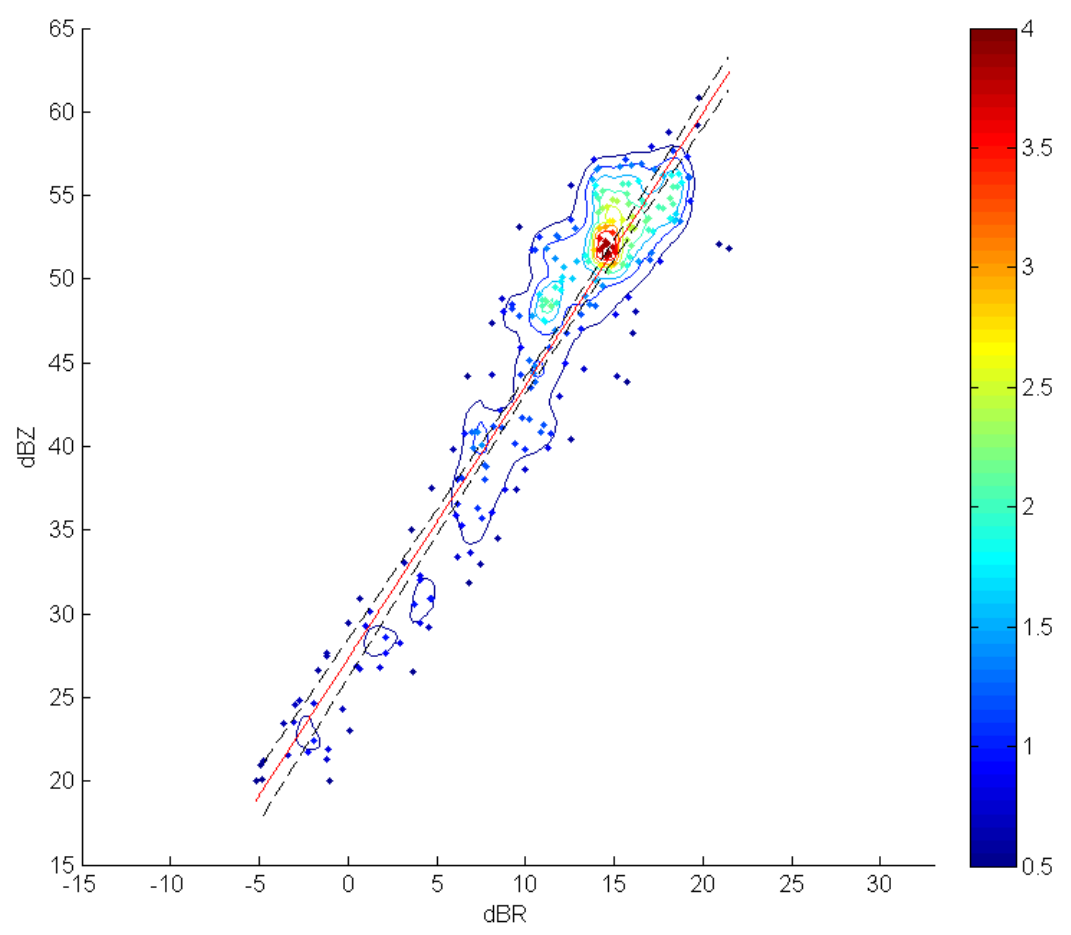

Fig. 6. Z-R functional relationships for Warsaw, developed for hail precipitation based on laser disdrometer records. Local density of often overlapped experimental point is shown as color map with isolines. This fitted linear model is plotted as solid line and its $95 \%$ confidence intervals are drawn by dotted lines.

ameters, which obviously could not be expected for snow. Indeed, for rain and rain-with-snow precipitation types, the $b$ parameter estimates from Warsaw (Table 3) matched exactly the theoretical values postulated by Dotzek and Beheng (2001). Note that not only the rain and rain-with-snow but also the snow and hail $b$ parameters reported in Table 3 were at the expected range of this parameter from $b=7 / 4$ to $b=7 / 5$, as suggested by Dotzek and Beheng (2001).

The most prominent departure from Marshall's and Palmer's (1948) postulated Z-R relationship was noticed for hail precipitation. Both $a$ and $b$ parameters had the highest values among all four precipitation-type groups. Parameter $a$ was more than twice as large for hail as for rain and almost six times larger than the snow-type Z-R relationship. At the same time, hail's value was characterized by the widest $95 \%$ confidence range, from 460 to 714. However, this parameter was far from the ROC recommended Z-R relationship for hail with a parameter estimated to be as high as 8400 . Differ- 
ences could be attributed to the contrast in precipitation conditions between Poland and, for example, the central plains of the USA. Evidently, the parameters derived for hail in Warsaw were much closer to the values of $a$ and $b$ equal to 500 and 1.5, respectively, and postulated by Joss et al. (1970) for convective thunderstorms.

\section{SUMMARY AND CONCLUSIONS}

The continuous precipitation monitoring in Warsaw by means of the Parsivel 2 disdrometer at high temporal resolution of 10 -seconds allowed us to obtain DSD sets representative of general precipitation types, as well as their derivatives in the form of radar reflectivity $Z$ and rain rate $R$ values. Based on these approximately two-year long disdrometer recordings, we assessed the share of different types of precipitation in total precipitation duration time and we estimated their contribution to the overall precipitation total. We derived empirical relationships between radar reflectivity $Z$ and rain rate $R$ for four different precipitation type groups: rain, rain-with-snow, snow, and hail. Based on these results and their analysis, we formulated the following conclusions:

- The local precipitation process in Warsaw is clearly dominated by rain. The share of snow precipitation duration time and its contribution to overall precipitation total is about three times smaller in comparison to rain. The similar share of time and contribution to the overall precipitation duration time and total in the case of other precipitation types is at the range of 1 or $2 \%$ percent of even less.

- As expected a priori for dependent experimental series calculated from DSDs, for all precipitation types, we observed a very good correlation between radar reflectivity $Z$ and rain rate $R$. The relationship between both parameters was effectively modelled by the exponential function. The Z-R relationship parameters were easily estimated using logarithmic regression and they are in the range of theoretically postulated values.

- The Z-R relationships for rain and rain-with-snow are showing a strong resemblance to each other. They are also close to the well-known Z-R relationships for rain, originally introduced by Marshall and Palmer (1948). The observed resemblance of Z-R relationships for rain and sleet may partly result from possible errors of both precipitation types classification, as there is no strict definition of sleet in terms of mixing ratio.

- The Z-R relationships for snow and hail clearly diverge from rain-type relationships. In the case of snow precipitation, both $a$ and $b$ parameters in the Z-R formula are smaller than for rain. In contrast, for hail precipitation these parameters are higher than for rain. Bearing this in mind, the introduction of snow- and hail-specific Z-R relationships to radar data 
processing in Poland could improve the quality of radar precipitation estimates.

The development of precipitation-type specific Z-R relationships in Poland should be continued in the future based on longer datasets, allowing for more detailed precipitation-type separation. Additional studies are necessary for the quantitative assessment of precipitation-type dependent Z-R use impact on of radar derived hydrology products.

Acknowledgements. This study was financed by the Polish National Science Centre (NCN) allocated on the basis of Decision No. 2011/03/B/ ST10/06338 under the project called "Spatio-temporal analysis and modeling of urban precipitation field". The Rose and Joseph Summers Endowment at the University of Iowa supported the second author.

\section{References}

Bech, J., V. Vidal, J.A. Ortiz, N. Pineda, and R. Veciana (2014), Real-time estimation of surface precipitation type merging weather radar and automated station observations. In: Abstracts $17^{\text {th }}$ International Road Weather Conference, 30 January - 1 February 2014, Andorra.

Bringi, V.K., and V. Chandrasekar (2001), Polarimetric Doppler Weather Radar: Principles and Applications, Cambridge University Press.

Ciach, G.J., and W.F. Krajewski (1999), Radar-rain gauge comparisons under observational uncertainties, J. Appl. Meteorol. 38, 10, 1519-1525, DOI: 10.1175/1520-0450(1999)038<1519:RRGCUO >2.0.CO;2.

Cyr, I. (2014), Estimation of Z-R relationship and comparative analysis of precipitation data from colocated rain-gauge, vertical radar and disdrometer, M.Sc. Thesis, Norwegian University of Science and Technology, Department of Hydraulic and Environmental Engineering, available from: http://www. diva-portal.org/smash/get/diva2:749367/FULLTEXT01.pdf.

Dotzek, N., and K.D. Beheng (2001), The influence of deep convective motions on the variability of Z-R relations, Atmos. Res. 59-60, 15-39, DOI: 10.1016/ S0169-8095(01)00107-7.

Gill, R.S., M.B. Soerensen, T. Boevith, J. Koistinen, M. Peura, D. Michelson, and R. Cremonini (2012), BALTRAD dual polarization hydrometeor classifier. In: Abstracts ERAD 2012 - 7th European Conference on Radar in Meteorology and Hydrology, 25-29 June 2012, Toulouse, France.

Gjertsen, U., and V. Ødegaard (2005), The water phase of precipitation - a comparison between observed, estimated and predicted values, Atmos. Res. 77, 218231, DOI: 10.1016/j.atmosres.2004.10.030. 
Jakubiak, B., P. Licznar, and S.P. Malinowski (2014), Rainfall estimates from radar versus rain gauge measurements. Warsaw case study, Environ. Prot. Eng. 40, 2, 162-170, DOI: 10.5277/epe140212.

Joss, J.K., K. Schram, J.C. Thams, and A. Waldvogel (1970), On the quantitative determination of precipitation by radar, Wissenschaffliche Mineilungen, No. 63, Eidgenossisichen Komission Zum Studium der Hagelbildung und der Hagelawehr.

Lee, G., and I. Zawadzki (2005), Variability of drop size distributions: Time-scale dependence of the variability and its effects on rain estimation, J. Appl. Meteorol. 44, 2, 241-255, DOI: 10.1175/JAM2183.1

Licznar, P. (2009), Wstępne wyniki porównawczych testów polowych elektronicznego deszczomierza wagowego OTT Pluvio2 i disdrometru laserowego Parsivel, Instal. 7-8, 43-50 (in Polish).

Licznar, P., and K. Siekanowicz-Grochowina (2015), Application of laser disdrometer to weather radar image calibration in the example of Warsaw, Ochr. Sr. 37, 2, 11-16 (in Polish).

Licznar, P., C. De Michele, and W. Adamowski (2015), Precipitation variability within an urban monitoring network via microcanonical cascade generators, Hydrol. Earth Syst. Sc. 19, 1, 485-506, DOI: 10.5194/hess-19-485-2015.

Marshall, J.S., and W. McK. Palmer (1948), The distribution of raindrops with size, J. Meteorol. 5, 4, 165-166, DOI: 10.1175/1520-0469(1948)005<0165: TDORWS $>2.0 . \mathrm{CO} ; 2$.

Marshall, J.S., R.C. Langille, and W. McK. Palmer (1947), Measurement of rainfall by radar, J. Meteorol. 4, 186-192, DOI: 10.1175/1520-0469(1947)004 $<0186$ :MORBR $>2.0 . \mathrm{CO} ; 2$.

Ochou, A.D., E.-P. Zahiri, B. Bamba, and M. Koffi (2011), Understanding the variability of Z-R relationships caused by natural variations in raindrop size distributions (DSD): Implication of drop size and number, Atmos. Clim. Sci. 1, 147-164, DOI: 10.4236/acs.2011.13017.

OFCM (2005), Doppler Radar Meteorological Observations. Part B: Doppler Radar Theory and Meteorology, Federal Meteorological Handbook No. 11, FCM-H11B-2005, WSR-88D, U.S. Department of Commerce, National Oceanic and Atmospheric Administration, Washington DC.

OTT (2015), Present Weather Sensor OTT Parsivel 2. Operating instructions, Document No. 70.210.001.B.E, OTT Hydromet GmbH, available from: http:// www.tecnologiayambiente.com.ar/wp-content/uploads/Manual_Parsivel2. pdf (accessed: April 2015).

Szturc, J., K. Ośródka, and A. Jurczyk (2011), Quality index scheme for quantitative uncertainty characterization of radar-based precipitation, Meteorol. Appl. 18, 4, 407-420, DOI: 10.1002/met.230.

Vasiloff, S.V. (2002), Investigation of a WSR-88D Z-R relation for snowfall in northern UTAH. In: Abstracts 16th Conference on Hydrology AMS, 12-17 January 2002, Orlando, USA, 3.18. 
Villarini, G., and W.F. Krajewski (2010), Review of the different sources of uncertainty in single polarization radar-based estimates of rainfall, Surv. Geophys. 31, 1, 107-129, DOI: 10.1007/s10712-009-9079-x.

Received 10 November 2015

Received in revised form 7 March 2016

Accepted 12 April 2016 